\title{
Emergency valve-sparing aortic root replacement and coronary artery bypass grafting for giant left sinus of Valsalva aneurysm presenting as acute coronary syndrome
}

\author{
Albert J. Pedroza, MD, Zachary E. Brewer, MD, and Anson M. Lee, MD Stanford, Calif
}

\author{
From the Department of Cardiothoracic Surgery, Stanford University, Stanford, Calif. \\ There are no funding sources for this work. \\ Disclosures: Authors have nothing to disclose with regard to commercial support. \\ Received for publication Dec 12, 2017; revisions received Feb 28, 2018; accepted for publication March 5, 2018; \\ available ahead of print March 31, 2018. \\ Address for reprints: Albert J. Pedroza, MD, Department of Cardiothoracic Surgery, Stanford University, 300 Pas- \\ teur Dr, Falk CVRB, Stanford, CA 94305 (E-mail: alpedroz@stanford.edu). \\ J Thorac Cardiovasc Surg 2018;156:e81-4 \\ $0022-5223 / \$ 36.00$ \\ Copyright $(2018$ by The American Association for Thoracic Surgery \\ https://doi.org/10.1016/j.jtcvs.2018.03.009
}

Video clip is available online.

Sinus of Valsalva aneurysm (SVA) is a rare condition that in a small fraction of cases appears as acute coronary syndrome. ${ }^{1}$ We present the case of a patient with SVA who sought treatment for coronary symptoms and underwent successful valve-sparing aortic root replacement with concomitant coronary artery bypass grafting.

\section{CLINICAL SUMMARY}

A 52-year-old woman with hypertension came to a local emergency department with acute chest pain after 1 week of subacute chest discomfort and dyspnea. An electrocardiogram demonstrated lateral T-wave inversions, and her serum troponin was elevated, prompting urgent coronary catheterization. Coronary angiography revealed a giant left SVA compressing her left main coronary artery (Figure 1, $A$ and $B$, and Videos 1 and 2). There was moderate to severe aortic insufficiency. Accordingly, the patient was transferred to a tertiary referral center for consideration of urgent surgical intervention.

On arrival at our institution, the patient continued to have dull chest pressure. She underwent chest computed tomographic angiography, which demonstrated a large isolated aneurysm of the left sinus of Valsalva measuring $5.1 \times 5.3 \times 3.8 \mathrm{~cm}$ and associated with severe proximal stenosis of the left main coronary artery (Figure 1,C). The remainder of the thoracic aorta was unremarkable, other than a 4-vessel aortic arch. button aneurysm.

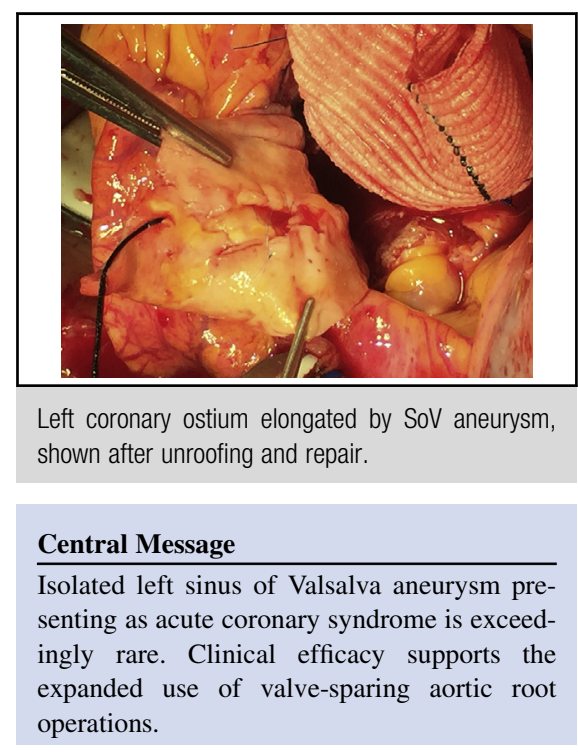

See Editorial Commentary page e85.

The patient was brought to the operating room and placed under general anesthesia. Transesophageal echocardiography revealed moderate to severe eccentric aortic insufficiency, preserved left ventricular function, and the known aneurysm (Video 3). After median sternotomy, the left internal thoracic artery was harvested in anticipation of the need for coronary revascularization. After cardiopulmonary bypass initiation and cardioplegia administration, the aorta was transected, and the right coronary and noncoronary sinuses were excised. The right coronary artery was prepared for reimplantation. Inspection of the left sinus revealed a large, 2-cm opening into the aneurysm, with a small, slitlike coronary ostium originating from the aneurysm. The left main coronary artery was essentially intramural; this was unroofed with Potts scissors, and the cut edges were oversewn with 6-0 Prolene (Ethicon Inc, Somerville, NJ) suture (Figure 2, A). The revised ostium was prepared for reimplantation and trimmed to minimize the residual aortic tissue and risk of coronary

The aneurysmal left sinus was then excised entirely, and the decision was made to proceed with a valve-sparing aortic root replacement. The valve was resuspended into a 28-mm woven Dacron polyester fabric graft. On aortic valve competency testing, the left cusp was noted to have 


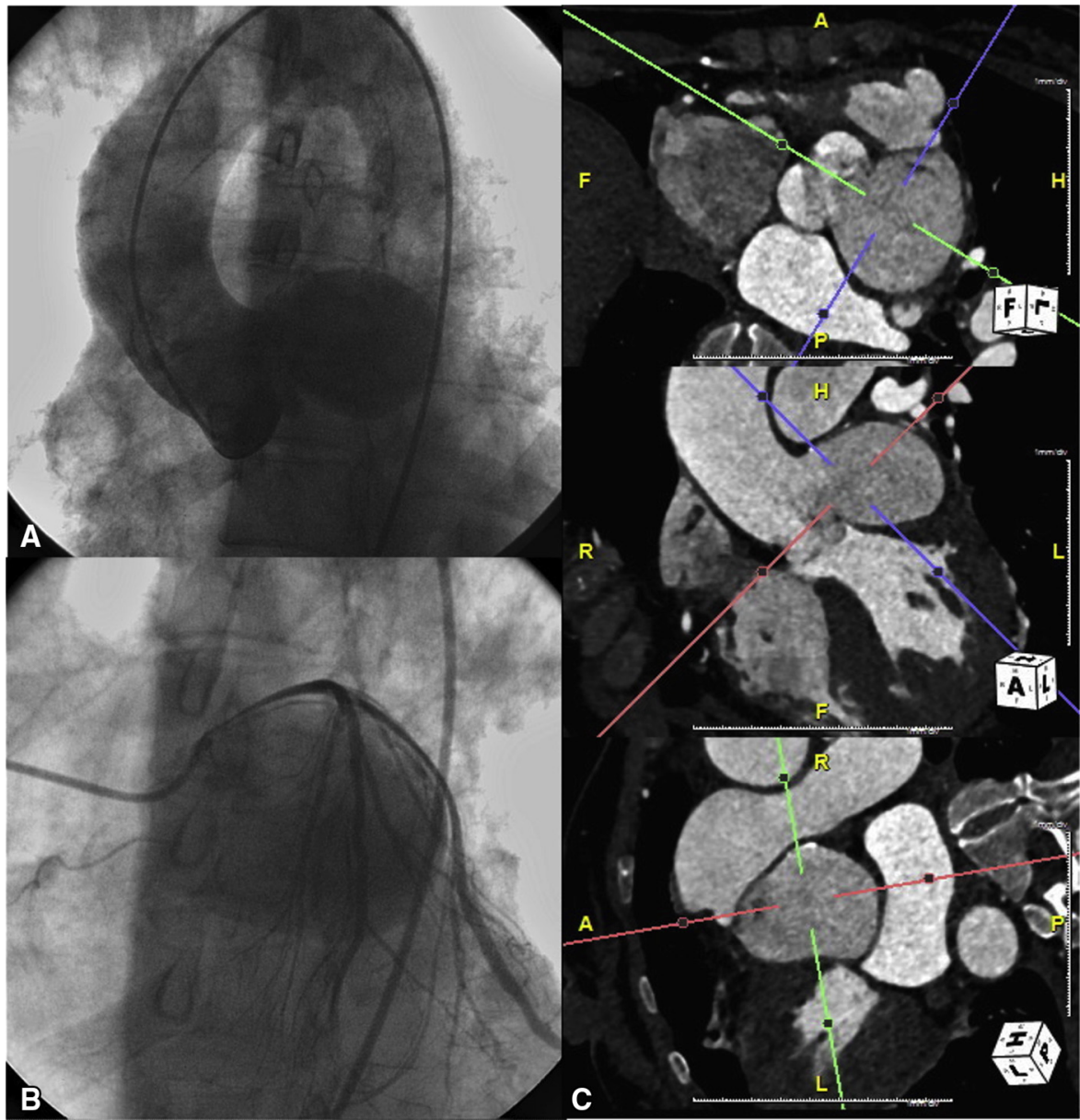

FIGURE 1. A, Aortogram revealing a large, unruptured left sinus of Valsalva aneurysm with a wide mouth. B, Selective catheterization of left main coronary artery with ostial stenosis and elongated, compressed left main segment. C, Multiplanar orthogonal slices of preoperative computed tomographic angiography showing giant aneurysm isolated to left sinus of Valsalva and distortion of aortic valve leaflets. $A$, Anterior; $F$, foot; $H$, head; $P$, posterior; $L$, left; $R$, right.

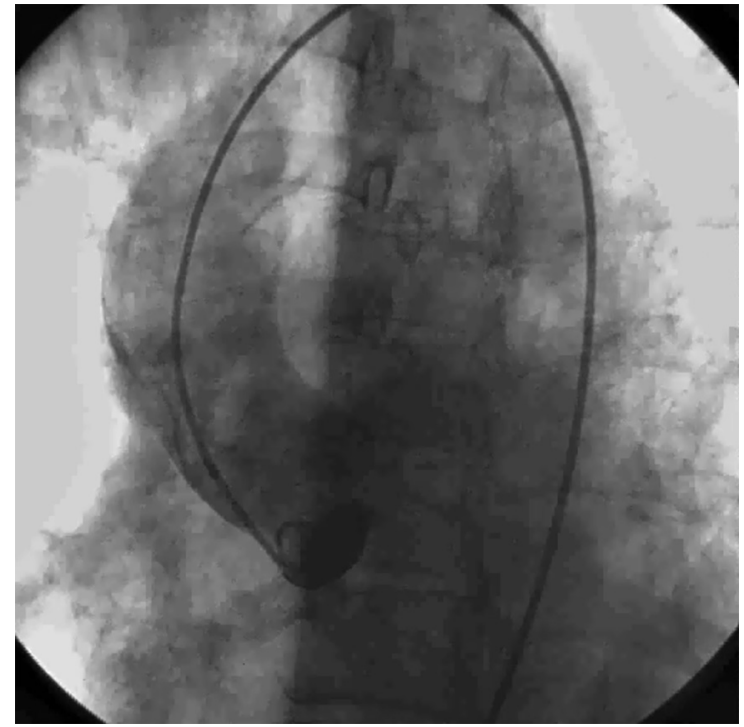

VIDEO 1. Aortogram with large left sinus of Valsalva aneurysm with wide mouth and nonlaminar flow. Video available at: http://www. jtcvsonline.org/article/S0022-5223(18)30699-8/fulltext.

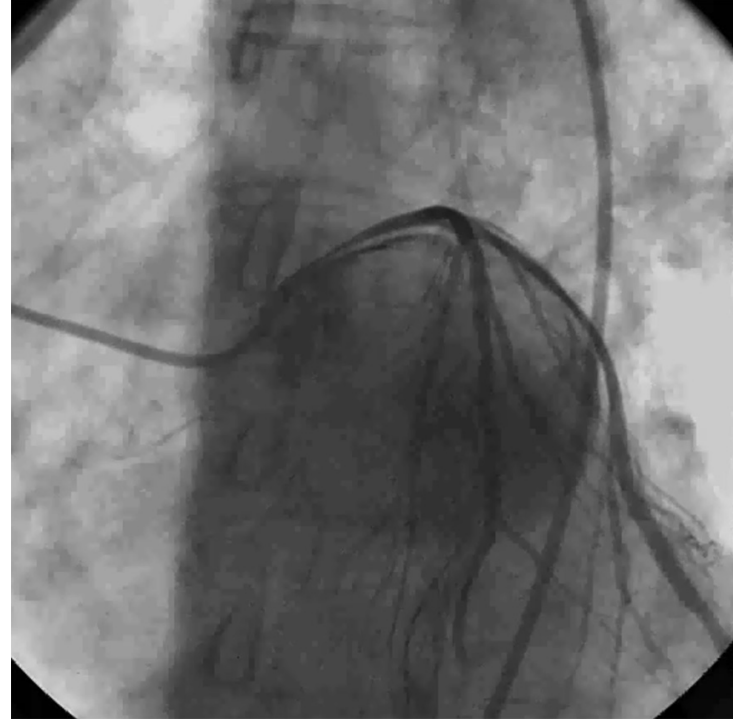

VIDEO 2. Left coronary angiography with ostial stenosis and extrinsic compression by large aneurysm sac. Video available at: http://www. jtcvsonline.org/article/S0022-5223(18)30699-8/fulltext. 


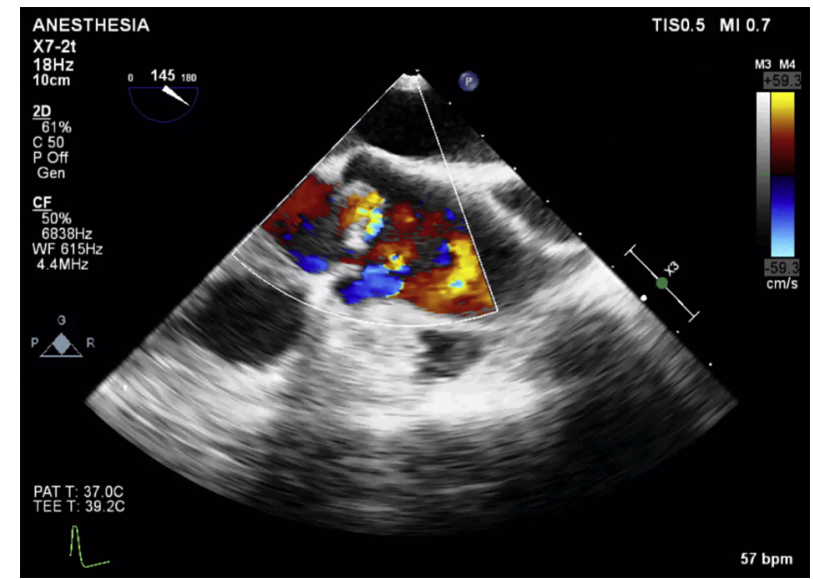

VIDEO 3. Transesophageal echocardiogram LVOT long axis view demonstrating moderate-severe aortic insufficiency and distorted leaflet anatomy. Video available at: http://www.jtcvsonline.org/article/S00225223(18)30699-8/fulltext.

an elongated free edge and significant prolapse. The free edge was plicated with a pledgeted 6-0 GORE-TEX (William L. Gore \& Associates, Flagstaff, Ariz) suture near the left coronary-noncoronary commissure, with improved leaflet coaptation height (Figure 2, B) and no appreciable leak under static pressure testing. The coronary buttons were then reimplanted, and the aortic root graft was anastomosed to the transected ascending aorta (Figure 2,C). The harvested left interior thoracic artery was grafted to the left anterior descending artery. On reperfusion, an intra-aortic balloon pump was placed for inferior left ventricular hypokinesis, and the patient was

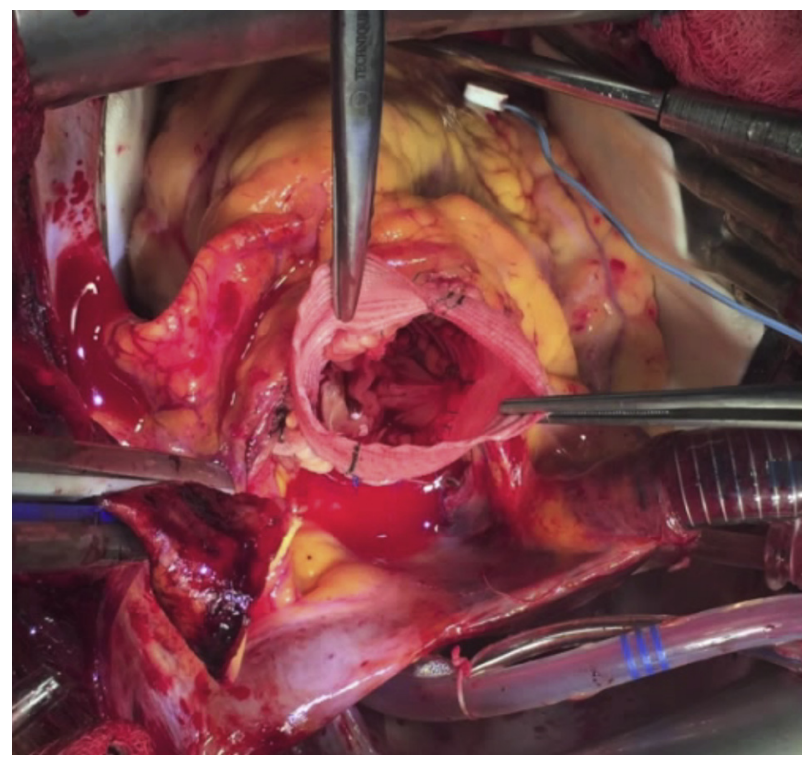

VIDEO 4. Case summary, imaging, and technical details. LIMA, Left internal thoracic artery; $C P B$, cardiopulmonary bypass; $R C A$, right coronary artery; Mid Asc, mid ascending. Video available at: http://www. jtcvsonline.org/article/S0022-5223(18)30699-8/fulltext.

separated from cardiopulmonary bypass with trace aortic insufficiency.

The patient was extubated the day after surgery, and the balloon pump was removed the next day. She was discharged home on postoperative day 11. At follow-up 1 month after surgery, the patient reported gradual return of functional stamina, and transthoracic echocardiography demonstrated normal left ventricular function with mild aortic insufficiency.
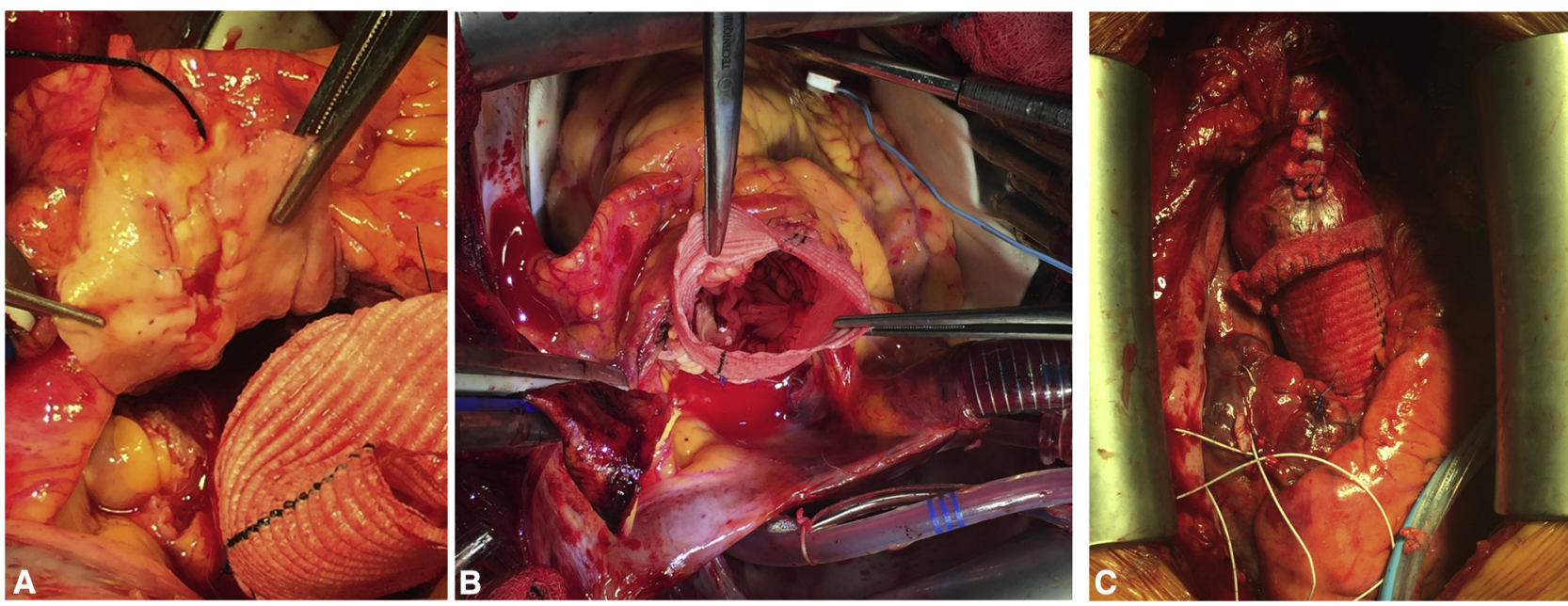

FIGURE 2. A, Elongated, intramural left coronary ostium widely unroofed and repaired with interrupted Prolene (Ethicon Inc, Somerville, NJ) sutures before preparation for reimplantation into the aortic root graft (bottom right). B, Reimplanted trileaflet aortic valve with adequate leaflet coaptation and restored aortic root geometry viewed from the surgeon's perspective. A single plicating suture was placed in the left cusp to restore the appropriate free margin length and resolve leaflet prolapse into the outflow tract. C, After repair and coronary reimplantation. 


\section{DISCUSSION}

SVA is a rare condition, with a small fraction of cases presenting as acute coronary syndrome. ${ }^{1}$ In experienced centers, valve-sparing aortic root replacement for "expanded indications" has become a viable surgical plan, even in acute aortic emergencies including right SVA with fistulization to the right ventricle. ${ }^{2,3}$ Historical reports of similar cases describe multiple methods or repair, including patch closure of the aneurysm mouth and composite valve graft root replacements. ${ }^{4,5}$ Given our patient's young age and the likelihood that restoration of proper aortic root geometry would resolve her valvular insufficiency, we elected to proceed with a valve-sparing approach. Our standard approach for valve-sparing operations is a modified David reimplantation technique. We elected not to use a remodeling technique for this isolated left SVA out of concern for late annular dilatation and valve incompetency.

Our preoperative angiographic findings revealed ostial left main compromise superimposed on extrinsic compression by mass effect of the aneurysm, and we therefore planned for distal revascularization at the beginning of the operation. Interestingly, it appeared that the large aneurysm had resulted in the left main coronary artery becoming almost entirely intramural. Despite unroofing and reimplantation of the native coronary artery, the long segment of stenosis on preoperative catheterization made revascularization critical to ensure adequate left ventricular perfusion.

To our knowledge, this is the first use of a valve-sparing approach to the treatment of a left SVA presenting with acute coronary syndrome (Video 4). We believe that this case further emphasizes the utility of valve-sparing aortic root replacement in clinically applicable cases.

\section{References}

1. Moustafa S, Mookadam F, Cooper L, Adam G, Zehr K, Stulak J, et al. Sinus of Valsalva aneurysms - 47 years of a single center experience and systematic overview of published reports. Am J Cardiol. 2007;99:1159-64.

2. Lesshnower BG, Guyton RA, Myung RJ, Puskas JD, Kilgo PD, McPherson L, et al. Expanding the indications for the David V aortic root replacement: early results. J Thorac Cardiovasc Surg. 2012;143:879-84

3. Woo YJ, Frederick JR. Valve-sparing aortic root replacement and neochordal repair of complex aortic leaflet pathology for ruptured sinus of Valsalva aneurysm fistulizing to the right ventricle. Ann Thorac Surg. 2013;96:1891-3.

4. Lijoi A, Parodi E, Passerone GC, Scarano F, Caruso D, Iannetti MV. Unruptured aneurysm of the left sinus of Valsalva causing coronary insufficiency: case report and review of the literature. Tex Heart Inst J. 2002;29:40-4.

5. Takach TJ, Reul GJ, Duncan JM, Cooley DA, Livesay JJ, Ott DA, et al. Sinus of Valsalva aneurysm or fistula: management and outcome. Ann Thorac Surg. 1999; 68:1573-7. 